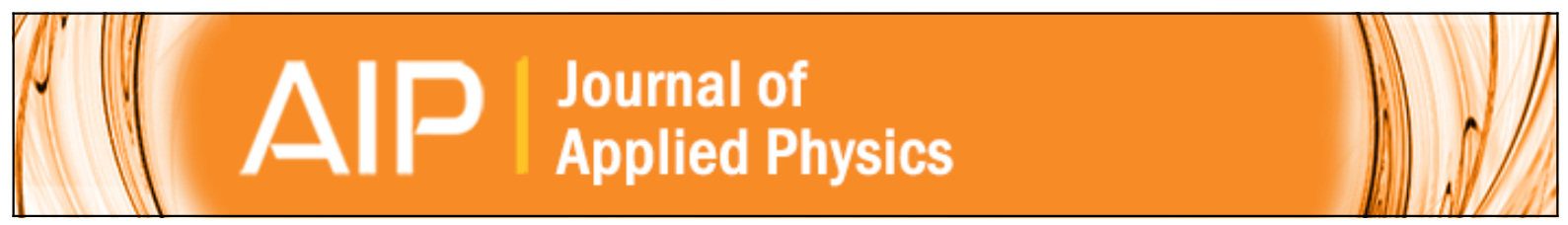

Intermetallic phases formed during tin implantation into iron and steels

P. H. Dionisio, B. A. S. de Barros Jr., and I. J. R. Baumvol

Citation: Journal of Applied Physics 55, 4219 (1984); doi: 10.1063/1.333022

View online: http://dx.doi.org/10.1063/1.333022

View Table of Contents: http://scitation.aip.org/content/aip/journal/jap/55/12?ver=pdfcov

Published by the AIP Publishing

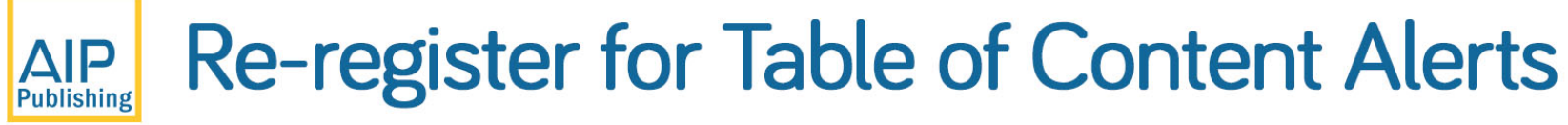

Create a profile.

Sign up today! 


\title{
Intermetallic phases formed during tin implantation into iron and steels
}

\author{
P. H. Dionisio, B. A. S. de Barros, Jr., and I. J. R. Baumvol \\ Instituto de Física, Universidade Federal do Rio Grande do Sul, 90000 Porto Alegre, RS, Brasil
}

(Received 20 June 1983; accepted for publication 9 September 1983)

\begin{abstract}
The surface layers of pure iron, high-carbon steel and stainless steel, ion implanted with $1 \times 10^{17}$ $\mathrm{Sn}^{+} \mathrm{cm}^{-2}$, have been characterized by means of ${ }^{119} \mathrm{Sn}$ conversion electrons Mössbauer scattering. The intermetallic phases existent in the as-implanted samples are determined, and then the thermal decomposition of these phases are established. The phase transformations observed in the treated surfaces agree reasonably well with the phase diagrams reported in the literature for stoichiometric intermetallic phases formed in bulk.
\end{abstract}

PACS numbers: $68.20+\mathrm{t}, 61.70 . \mathrm{Tm}, 64.70 . \mathrm{Kb}, 76.80 .+\mathrm{y}, 97.20 . \mathrm{Kz}$

\section{INTRODUCTION}

In recent years several authors reported modifications of the mechanical and high temperature oxidation properties of iron, steels, titanium, and other metals, caused by ion implantation or ion beam mixing of tin into the surface layers of these materials. ${ }^{1-8}$

The reductions observed in the wear rate and friction coefficient after treating the metal surface by the two above processes may be due to precipitation hardening, since second phase precipitates such as $\mathrm{FeSn} \mathrm{n}_{2}$ and $\mathrm{Ni}_{3} \mathrm{Sn}_{2}$ which can account for hardening are formed during implantation.

The improved resistance to high temperature oxidation in the case of pure iron implanted with $\mathrm{Sn}^{+}$ions was associated with the intermetallic $\mathrm{FeSn}_{2}$. This was established in analogy with tinplating, where $\mathrm{FeSn}_{2}$ acts as a barrier between the active iron substrate and the oxidizing environment, reducing greatly the surface area of the iron that is sacrificially protected by $\mathrm{SnO}_{2}{ }^{9}$ Oxidative wear is also influenced by this mechanism. ${ }^{1,2}$

These introductory remarks emphasize the existence of a large interest on the characterization of the phases formed on the surface of the above mentioned materials when they are implanted with $\mathrm{Sn}$, as well as the relative proportion of these phases and the kind of transformations that they experience when the samples are submitted to temperatures typical of the practical working conditions. Such a knowledge is essential for the understanding of mechanisms responsible for the protective effects that are observed, and also to be able to predict the most promising applications.

In the present paper we report on the determination of intermetallic phases on pure iron, tool (high-carbon, lowchromium) steel and stainless (18/8) steel implanted with $\mathrm{Sn}^{+}$ions. The method used to determine the phases formed during implantation and their thermal evolution was the following.

(i) ${ }^{119} \mathrm{Sn}$ conversion electron Mössbauer scattering (CEMS) analysis is performed on the as-implanted surfaces. ${ }^{10-12}$ The components used to fit the CEMS spectra are identified by comparison with data on transmission Mössbauer spectroscopy of stoichiometric intermetallic compounds from the literature.

(ii) The samples from (i) are annealed in high vacuum at temperatures in the range $200-900^{\circ} \mathrm{C}$. After every annealing temperature a CEMS spectrum is recorded. By comparing the new parameters for each component of the fitting with the Mössbauer data from the literature we can establish the phase transformations occurring at the surface of the samples.

(iii) The phase transformation schemes obtained in the present work are then compared with the phase diagrams for the $\mathrm{Fe}-\mathrm{Sn}$ and also for the Ni-Sn systems (there are no C-Sn nor $\mathrm{Cr}$-Sn intermetallics). This comparison allows in most cases a rather unambiguous determination of the kind of precipitates formed during implantation and their thermal evolution.

\section{EXPERIMENTAL RESULTS}

Samples of pure iron $(99.99 \%)$, ground and polished $\mathrm{NSOH}$ tool steel $(1 \mathrm{C}, 0.5 \mathrm{Cr}, 1.2 \mathrm{Mn}, 0.5 \mathrm{~W}$ ) and polished $18 / 8 / 1$ stainless steel $(0.15 \mathrm{C}, 18 \mathrm{Cr}, 8 \mathrm{Ni}, 2 \mathrm{Mn})$ were all electropolished and then implanted with $1 \times 10^{17}$ ${ }^{119} \mathrm{Sn}^{+} \mathrm{cm}^{-2}$ at $200 \mathrm{keV}$ in the Linttot facility at Harwell. Typical depth profiles for the implanted $\mathrm{Sn}^{+}$are given in Ref. 1.

The CEMS data were obtained in a backscattering geometry. A proportional counter in which $\mathrm{He}-5 \% \mathrm{CH}_{4}$ was allowed to flow was added to a conventional constant acceleration Mössbauer spectrometer. In this experimental setup the samples are placed inside the detector and all the conversion electrons with energies below $20 \mathrm{keV}$ are collected on a tungsten wire. Further experimental details as well as the data reduction and analysis procedures can be obtained in Refs. 10 and 11. The Mössbauer source used was ${ }^{119 m} \mathrm{Sn}$ in $\mathrm{BaSnO}_{3}$. All the isomer shifts are quoted with respect to this source.

In Fig. 1 we show our CEMS spectra for the as-implanted samples. The lines through the data points are leastsquare fits to the experimental points. The subspectra composing the fitting for each experimental curve are also indicated. In Table I we give the parameters obtained from the fittings, and also the Mössbauer parameters for the corresponding phases as given in the literature. Intermetallic compound precipitates can in principle be identified by comparing the parameters from the present work (corresponding to nonstoichiometric, heavily damaged systems) with the 

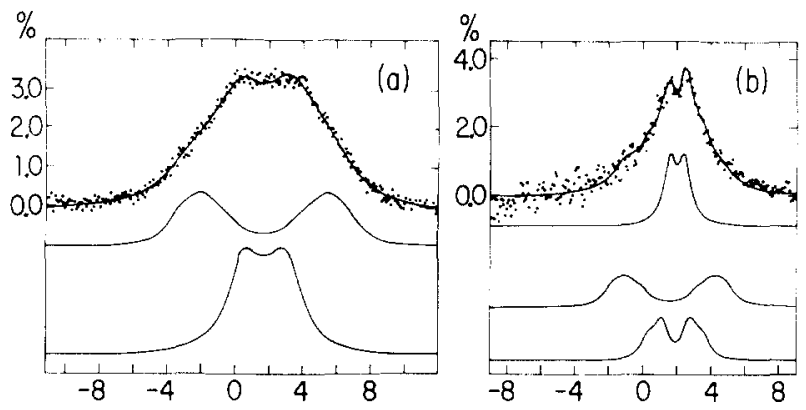

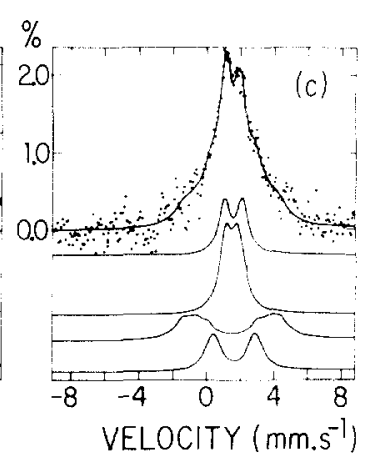

FIG. 1. ${ }^{119} \mathrm{Sn}$ CEMS spectra for the pure iron (a), tool steel (b), and stainless steel (c) samples, as-implanted with $1 \times 10^{17} \mathrm{Sn}^{+} \mathrm{cm}^{-2}$ at 200 $\mathrm{keV}$. The full lines accompanying the experimental points are least-squares fittings, and the subspectra composing the fittings are shown below each spectrum. The source was ${ }^{119 \mathrm{~m}} \mathrm{Sn}$ in $\mathrm{BaSnO}_{3}$ (see text and Table I). data for stoichiometric usually single phase systems that have been investigated by transmission Mössbauer spectroscopy by other authors.

For pure iron [Fig. 1(a) and Table I] we see that $66 \%$ of the relative area of the CEMS spectrum for the implanted ${ }^{119} \mathrm{Sn}$ corresponds to the intermetallic $\mathrm{FeSn}_{2}$, and $34 \%$ appears to be due to a solid solution of $\mathrm{Sn}$ in $\mathrm{Fe}(\mathrm{FeSn})$ with variable concentration (reflected in the CEMS spectrum by large linewidths). From the magnitude of the hyperfine magnetic field of this last component, $H=76 \pm 4 \mathrm{kOe}$, we can assume a maximum concentration of $\mathrm{Sn}$ of $2 \%$ for the solid solution FeSn. ${ }^{13-16}$

In NSOH tool steel [Fig. 1(b) and Table I] $27 \%$ of the relative area of the spectrum corresponds to $\mathrm{FeSn}_{2}$ and $73 \%$ to the intermetallic compound FeSn.

Finally, in stainless steel [Fig. 1(c), Table I] we observe $22 \%$ of $\mathrm{FeSn}_{2}, 58 \%$ of $\mathrm{FeSn}$, and $20 \%$ of an intermetallic phase of $\mathrm{Sn}$ and $\mathrm{Ni}$, namely $\mathrm{Ni}_{3} \mathrm{Sn}_{2} \cdot{ }^{17,1 \%}$

The CEMS spectra for the three samples after annealing in high vacuum $\left(10^{-5} \mathrm{~Pa}\right)$, during $1 \mathrm{~h}$, at different temperatures are displayed in Fig. 2 (pure iron), Fig. 3 (NSOH tool steel), and Fig. 4 (stainless steel). The parameters from the least-squares fittings of the experimental points are given in Table II.

The surface composition of pure iron implanted with ${ }^{119} \mathrm{Sn}^{+}$does not change after annealing at $200{ }^{\circ} \mathrm{C}$ [Fig. 2(b)]. The annealing at $350^{\circ} \mathrm{C}$ brings about a new component [Fig. 2(c)], a singlet with isomer shift $\delta=1.8 \mathrm{~mm} \mathrm{~s}^{-1}$, whose nature is only made clear when one analyses the CEMS spectrum after annealing at $500^{\circ} \mathrm{C}$ [Fig. 1(d)]. This last annealing reveals the complete absence of $\mathrm{FeSn}_{2}$ and, on the other hand, the presence of new and well defined components (with rather smaller linewidths), that we can identify, by inspections of Tables I and II, as the intermetallic FeSn and a

TABLE I. Mössbauer parameters from the fitting of the ${ }^{119} \mathrm{Sn}$ CEMS spectra of three samples of the present work, as-implanted, and the Mössbauer parameters as given in the literature for the $\mathrm{Fe}-\mathrm{Sn}$ and $\mathrm{Ni}-\mathrm{Sn}$ phases of interest (see text). The isomer shifts are given relative to $\mathrm{SnO} \mathrm{O}_{2}$.

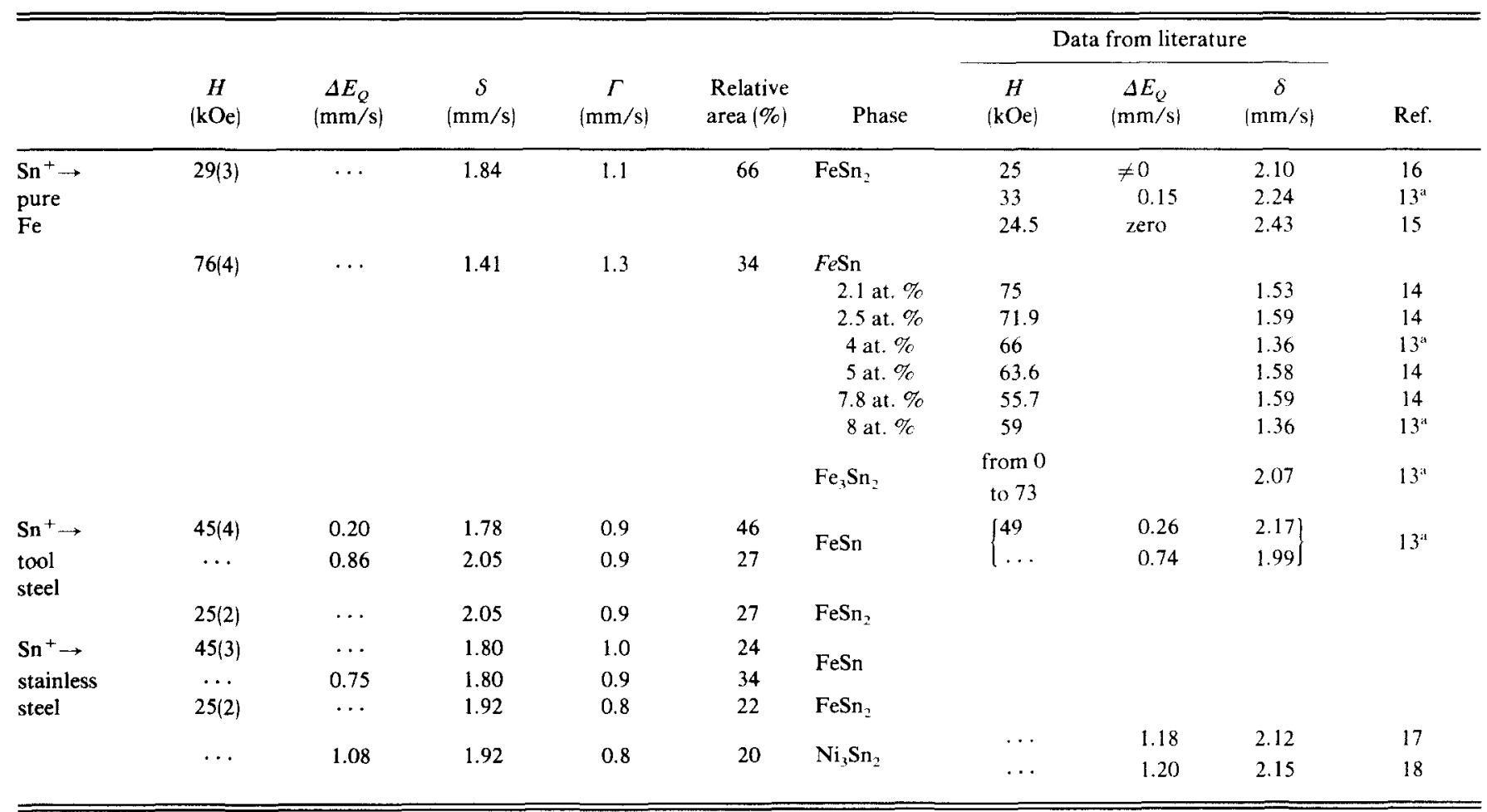

${ }^{a}$ Measured at $77 \mathrm{~K}$. 


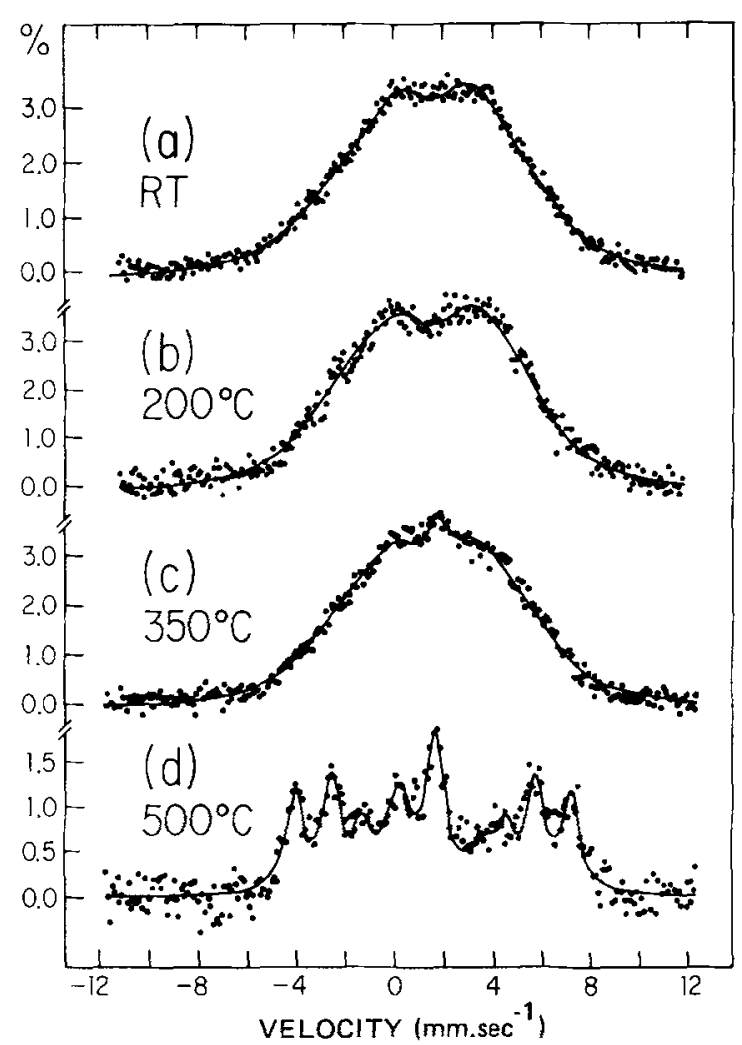

FIG. 2. ${ }^{119} \mathrm{Sn}$ CEMS spectra for the pure iron sample as-implanted (a), and after annealing in high vacuum at $200^{\circ} \mathrm{C}$ (b), $350^{\circ} \mathrm{C}$ (c), and $500^{\circ} \mathrm{C}$ (d) (see text and Table II)

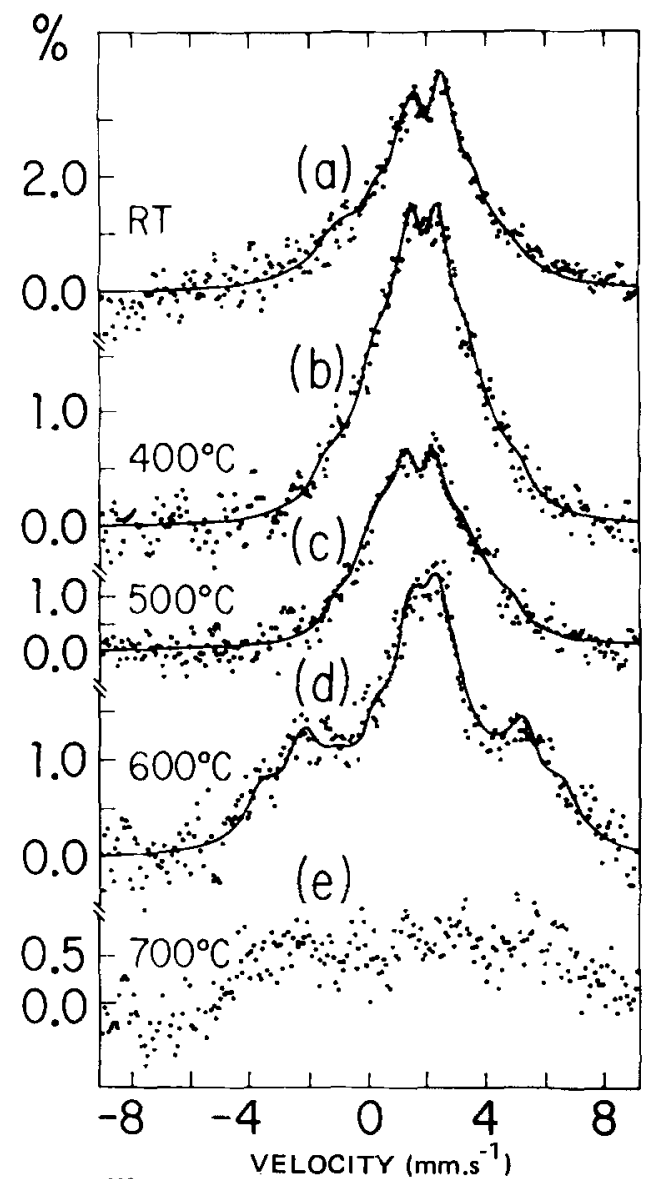

FIG. 3. ${ }^{119} \mathrm{Sn}$ CEMS spectra for the tool steel sample as-implanted (a), and after annealing in high vacuum at $400^{\circ} \mathrm{C}(\mathrm{b}), 500^{\circ} \mathrm{C}(\mathrm{c}), 600^{\circ} \mathrm{C}$ (d), and $700^{\circ} \mathrm{C}$ (see text and Table II).

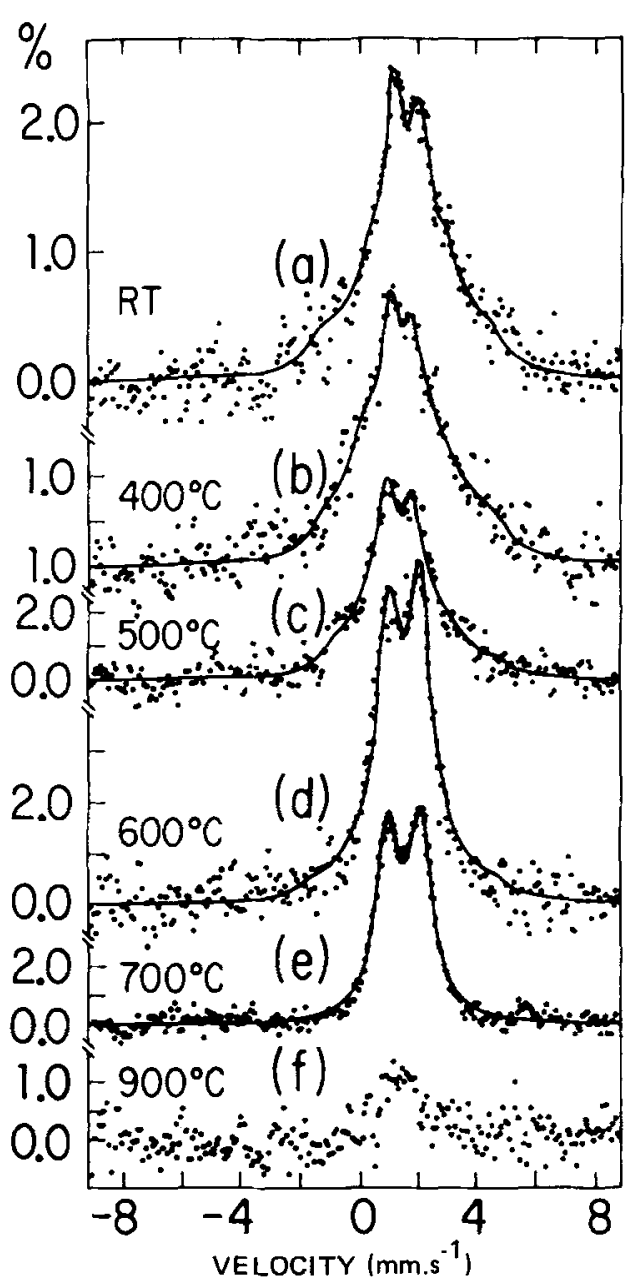

FIG. 4. "Sn CEMS spectra for the stainless steel sample as-implanted (a), and after annealing in high vacuum at $400^{\circ} \mathrm{C}$ (b), $500^{\circ} \mathrm{C}$, (c) $600{ }^{\circ} \mathrm{C}$ (d), $700^{\circ} \mathrm{C}(\mathrm{e})$, and $900^{\circ} \mathrm{C}(\mathrm{f})$ (see text and Table II).

solid solution FeSn with very small concentration of Sn (see Refs. 13 and 14). Then we can interpret the singlet of Fig. 1(c) as due to the incipient formation of FeSn at $350^{\circ} \mathrm{C}$.

The CEMS spectra for NSOH tool steel annealed at 400 and $500^{\circ} \mathrm{C}$ [Figs. 3(b) and $3(\mathrm{c})$ ] do not reveal any qualitative change in the surface composition. Only the relative areas corresponding to $\mathrm{FeSn}_{2}$ and $\mathrm{FeSn}$ change (see Table II) as well as the proportion between the two sites for ${ }^{119} \mathrm{Sn}$ in $\mathrm{FeSn}$. So, the relative area corresponding to $\mathrm{FeSn}_{2}$ decreases from $42 \%$ at $400{ }^{\circ} \mathrm{C}$ to $18 \%$ at $500{ }^{\circ} \mathrm{C}$, whereas the relative area corresponding to $\mathrm{FeSn}$ increases from $56 \%$ to $82 \%$ in the same temperature interval. After annealing at $600^{\circ} \mathrm{C}$ [Fig 3(d)] $\mathrm{FeSn}_{2}$ disappears completely from the CEMS spectrum. The only remaining compounds are $\mathrm{FeSn}(64 \%)$ and a new magnetic component with $H=76 \mathrm{kOe}$ (see Table II) that is again identified as $\mathrm{Sn}$ in solid solution in the steel matrix, with an average Sn concentration around $2 \%$ [we note here that the linewidths are larger in this solid solution as compared to the ones of Fig. 1(d) for pure iron]. Finally, annealing at $700^{\circ} \mathrm{C}$ [Fig. 3(e)] results in a further modification: all the previously existent phases disappear from the surface, leaving only a very poorly defined spectrum with very small absorption coefficient. This might well be due to 
TABI.E II. Missbaucr parameters from the fitting of the ${ }^{119} \mathrm{Sn}$ CEMS spectra of the present work taken after annealing in high vacuum at different temperatures. The isomer shifts are given relative to $\mathrm{SnO}_{2}$

\begin{tabular}{|c|c|c|c|c|c|c|c|}
\hline & $\begin{array}{c}\text { Annealing } \\
\text { temperature } \\
\left.l^{\circ} \mathrm{C}\right)\end{array}$ & $\begin{array}{c}H \\
(\mathrm{kOe})\end{array}$ & $\begin{array}{c}\Delta E_{Q} \\
(\mathrm{~mm} / \mathrm{s})\end{array}$ & $\begin{array}{c}\delta \\
(\mathrm{mm} / \mathrm{s})\end{array}$ & $\begin{array}{c}\Gamma \\
(\mathrm{mm} / \mathrm{s})\end{array}$ & $\begin{array}{c}\text { Relative } \\
\text { area } \\
(\%)\end{array}$ & Phase \\
\hline \multirow[t]{4}{*}{$\begin{array}{l}\mathrm{Sn}^{+} \rightarrow \\
\text { pure } \\
\end{array}$} & RT & $\begin{array}{l}29 \\
76\end{array}$ & $\begin{array}{l}\cdots \\
\cdots\end{array}$ & $\begin{array}{l}1.84 \\
1.41\end{array}$ & $\begin{array}{l}1.1 \\
1.3\end{array}$ & $\begin{array}{l}66 \\
34\end{array}$ & $\begin{array}{l}\mathrm{FeSn}_{2} \\
\mathrm{FeSn} 2 \text { at. \% } \\
\text { or } \mathrm{Fe}_{3} \mathrm{Sn}_{2}\end{array}$ \\
\hline & 200 & $\begin{array}{l}29 \\
73\end{array}$ & $\begin{array}{l}\cdots \\
\cdots\end{array}$ & $\begin{array}{l}1.75 \\
1.40\end{array}$ & $\begin{array}{l}1.1 \\
1.3\end{array}$ & $\begin{array}{l}66 \\
34\end{array}$ & $\begin{array}{l}\mathrm{FeSn}_{2} \\
\mathrm{FeSn} 2 \text { at. } \%\end{array}$ \\
\hline & 350 & $\begin{array}{r}29 \\
73 \\
0\end{array}$ & $\cdots$ & $\begin{array}{l}1.70 \\
1.40 \\
1.80\end{array}$ & $\begin{array}{l}1.1 \\
1.3 \\
0.8\end{array}$ & $\begin{array}{l}55 \\
32 \\
13\end{array}$ & $\begin{array}{l}\mathrm{FeSn}_{2} \\
\mathrm{FeSn} 2 \text { at. } \%\end{array}$ \\
\hline & 500 & $\begin{array}{l}81 \\
78 \\
43 \\
\ldots\end{array}$ & $\begin{array}{c}0.20 \\
0.46 \\
\ldots \\
0.71\end{array}$ & $\begin{array}{l}1.31 \\
1.74 \\
1.80 \\
1.62\end{array}$ & $\begin{array}{l}0.8 \\
0.8 \\
0.8 \\
0.9\end{array}$ & $\left.\begin{array}{l}32 \\
27 \\
22 \\
19\end{array}\right\}$ & $\begin{array}{l}F e S n<2 \text { at. \% } \\
F e S n<2 \text { at. \% } \\
\text { FeSn }\end{array}$ \\
\hline \multirow[t]{5}{*}{$\begin{array}{l}\mathrm{Sn}^{+} \rightarrow \\
\text { tool } \\
\text { steel }\end{array}$} & \multirow[t]{2}{*}{ RT } & $\begin{array}{l}45 \\
\ldots\end{array}$ & $\begin{array}{l}0.20 \\
0.86\end{array}$ & $\begin{array}{l}1.78 \\
2.05\end{array}$ & $\begin{array}{l}0.9 \\
0.9\end{array}$ & $\left.\begin{array}{l}46 \\
27\end{array}\right\}$ & $\mathrm{FeSn}$ \\
\hline & & 25 & $\cdots$ & 2.05 & 0.9 & 27 & $\mathrm{FeSn}_{2}$ \\
\hline & 400 & $\begin{array}{l}25 \\
50 \\
\ldots\end{array}$ & $\begin{array}{l}\cdots \\
\cdots \\
0.81\end{array}$ & $\begin{array}{l}1.87 \\
1.86 \\
1.90\end{array}$ & $\begin{array}{l}1.0 \\
1.0 \\
1.0\end{array}$ & $\left.\begin{array}{l}42 \\
24 \\
34\end{array}\right\}$ & $\begin{array}{l}\text { FeSn } \\
\text { FeSn }\end{array}$ \\
\hline & 500 & $\begin{array}{l}24 \\
45 \\
\cdots\end{array}$ & $\begin{array}{l}\cdots \\
\cdots \\
0.88\end{array}$ & $\begin{array}{l}1.70 \\
1.95 \\
1.80\end{array}$ & $\begin{array}{l}1.0 \\
1.0 \\
1.0\end{array}$ & $\left.\begin{array}{l}18 \\
46 \\
36\end{array}\right\}$ & $\begin{array}{l}\mathrm{FeSn}_{2} \\
\mathrm{FeSn}\end{array}$ \\
\hline & 600 & $\begin{array}{l}43 \\
\cdots \\
76\end{array}$ & $\begin{array}{c}\ldots \\
0.90 \\
\cdots \\
\text { Not fitted }\end{array}$ & $\begin{array}{l}1.63 \\
1.83 \\
1.49\end{array}$ & $\begin{array}{l}1.6 \\
1.3 \\
1.4\end{array}$ & $\left.\begin{array}{l}29 \\
35 \\
36\end{array}\right\}$ & FeSn \\
\hline \multirow[t]{5}{*}{$\begin{array}{l}\mathrm{Sn}^{+} \rightarrow \\
\text { stainless } \\
\text { steel }\end{array}$} & RT & $\begin{array}{c}45 \\
\ldots \\
25 \\
\ldots\end{array}$ & $\begin{array}{c}\ldots \\
0.75 \\
\ldots \\
1.08\end{array}$ & $\begin{array}{l}1.80 \\
1.80 \\
1.92 \\
1.92\end{array}$ & $\begin{array}{l}1.0 \\
0.9 \\
0.8 \\
0.8\end{array}$ & $\left.\begin{array}{l}24 \\
34 \\
22 \\
20\end{array}\right\}$ & $\mathrm{FeSn}$ \\
\hline & 400 & $\begin{array}{l}25 \\
45 \\
\ldots \\
\ldots\end{array}$ & $\begin{array}{l}\cdots \\
\cdots \\
0.73 \\
1.12\end{array}$ & $\begin{array}{l}1.80 \\
2.00 \\
1.72 \\
1.93\end{array}$ & $\begin{array}{l}0.8 \\
1.0 \\
0.9 \\
0.8\end{array}$ & $\left.\begin{array}{l}25 \\
25 \\
38 \\
12\end{array}\right\}$ & $\begin{array}{l}\mathrm{FeSn}_{2} \\
\mathrm{FeSn} \\
\mathrm{Ni}_{3} \mathrm{Sn}_{2}\end{array}$ \\
\hline & \multirow[t]{2}{*}{500} & $\begin{array}{l}23 \\
43\end{array}$ & $\ddot{0.30}$ & $\begin{array}{l}1.73 \\
2.01\end{array}$ & $\begin{array}{l}0.9 \\
0.9\end{array}$ & $\begin{array}{c}8 \\
29 \\
\end{array}$ & $\begin{array}{l}\mathrm{FeSn}_{2} \\
\mathrm{FeSn}\end{array}$ \\
\hline & & $\begin{array}{l}\cdots \\
45\end{array}$ & $\begin{array}{l}0.73 \\
1.10 \\
\ldots\end{array}$ & $\begin{array}{l}1.63 \\
1.69 \\
1.75\end{array}$ & $\begin{array}{l}0.9 \\
1.0 \\
1.0\end{array}$ & $\begin{array}{l}24] \\
39 \\
13]\end{array}$ & $\begin{array}{l}\mathrm{Ni}_{3} \mathrm{Sn}_{2} \\
\mathrm{FeSn}\end{array}$ \\
\hline & 600 & $\begin{array}{l}\cdots \\
\cdots \\
\cdots\end{array}$ & $\begin{array}{c}0.75 \\
1.16 \\
1.11 \\
\text { Not fitted }\end{array}$ & $\begin{array}{l}1.85 \\
1.73 \\
1.73\end{array}$ & $\begin{array}{l}1.0 \\
0.9 \\
0.9\end{array}$ & $\begin{array}{c}29 \\
58 \\
100\end{array}$ & $\begin{array}{l}\mathrm{FeSn} \\
\mathrm{Ni}_{3} \mathrm{Sn}_{2} \\
\mathrm{Ni}_{3} \mathrm{Sn}_{2}\end{array}$ \\
\hline
\end{tabular}

in- or out-diffusion of the implanted ${ }^{119} \mathrm{Sn}$, resulting in a very dilute solid solution.

In Fig. 4 we show the thermal evolution of the $18 / 8$ stainless steel sample. Again, as in the case of tool steel, there are only redistributions of the relative areas corresponding to $\mathrm{Ni}_{3} \mathrm{Sn}_{2}, \mathrm{FeSn}_{2}$, and $\mathrm{FeSn}$ in the CEMS spectra measured after annealing at 400 and $500^{\circ} \mathrm{C}$ [Figs. $4(\mathrm{~b})$ and $4(\mathrm{c})$ and Table II]. Annealing at $600^{\circ} \mathrm{C}$ [Fig. 4(d)] completely decomposes the $\mathrm{FeSn}_{2}$ leaving only $58 \%$ of $\mathrm{Ni}_{3} \mathrm{Sn}_{2}$ and $42 \%$ of FeSn. By annealing at $700^{\circ} \mathrm{C}$ [Fig. 4(e)] we decompose the FeSn intermetallic and the CEMS spectrum can be fitted exclusively with the quadrupole doublet identified with $\mathrm{Ni}_{3} \mathrm{Sn}_{2}$. Finally, the annealing at $900^{\circ} \mathrm{C}$ suggests the partial decomposition of $\mathrm{Ni}_{3} \mathrm{Sn}_{2}$ and the loss of ${ }^{119} \mathrm{Sn}$ from the surface, since the peak-to-background ratio is smaller than observed in the previous spectrum, although qualitatively similar.

\section{DISCUSSION AND CONCLUSIONS}

\section{A. Pure Iron}

The evidence for the intermetallic $\mathrm{FeSn}_{2}$ in the surface layers of pure iron implanted with $\mathrm{Sn}^{+}$is very satisfactory. The magnetic hyperfine fields and isomer shifts extracted from the CEMS spectra of the present work agree very well with transmission Mössbauer spectroscopy on stoichiome- 
tric, heat treated $\mathrm{FeSn}_{2}$ and also with the data obtained by CEMS observations on iron samples treated by means of tinplating, ${ }^{15}$ where it is known that only $\mathrm{FeSn}_{2}$ is formed. Moreover the thermal evolution displayed in Fig. 2 shows that $\mathrm{FeSn}_{2}$ decomposes at $500^{\circ} \mathrm{C}$ into $\mathrm{FeSn}$ plus free $\mathrm{Sn}$ in solid solution in the iron matrix. This is an agreement with the phase diagram for the Fe-Sn system where this decomposition occurs exactly at $496^{\circ} \mathrm{C} .{ }^{19-21}$

The most plausible interpretation for the other component of the fitting of the as-implanted pure iron sample from Fig. 1(a) is indeed a solid solution of $\mathrm{Sn}$ in Fe. The hyperfine field and isomer shift agree very well with the result of Ref. 14. However we cannot be conclusive about the origin of the large linewidths that we observe. They may well be due to a distribution of concentrations of $\mathrm{Sn}$ in $\mathrm{FeSn}$ or alternatively they may lead to a completely different interpretation of this component as being the intermetallic compound $\mathrm{Fe}_{3} \mathrm{Sn}_{2}$. Indeed, for this compound which is said to be stable in the temperature interval between 600 and $815^{\circ} \mathrm{C}$, Trumpy et $a l .{ }^{13}$ observed an unresolved spectrum probably made up of about four different magnetic components with hyperfine fields between zero and $73 \mathrm{kOe}$; however the isomer shifts that we measured do not agree with Trumpy's results. If we choose $\mathrm{FeSn}_{2}+\mathrm{FeSn}$ as the most probable interpretation, then we can see that by means of ion implantation we reached the region of the phase diagram of the Fe-Sn system ${ }^{19-21}$ where $\mathrm{FeSn}_{2}$ and $\mathrm{Sn}$ coexists, a situation which is only stable at high concentration of $\mathrm{Sn}$ (above $80 \mathrm{wt}$. \%) and temperatures below $300^{\circ} \mathrm{C}$.

The formation of $\mathrm{FeSn}$ and a more dilute solid solution $\mathrm{FeSn}$ after annealing at $500^{\circ} \mathrm{C}$ are, as we discussed above, very consistent with the phase diagram for the Fe-Sn system. ${ }^{19}$

The Mössbauer parameters extracted from our fittings agree reasonably well with the reported values. The only disagreement is in the relative areas of the magnetic and nonmagnetic (quadrupole interaction) sites for ${ }^{119} \mathrm{Sn}$ in $\mathrm{FeSn}$. This may eventually be due to the fact that we did not anneal the sample at temperatures higher than $500^{\circ} \mathrm{C}$, and higher temperatures might be necessary to prepare stoichiometric and crystallographically homogeneous FeSn.

\section{B. Tool steel}

The surface composition of as-implanted NSOH-tool steel is rather clear from the point of view of CEMS analysis and it is also consistent with the phase diagrams established by Edwards and Preece. ${ }^{19}$ The coexistence of the intermetallic phases $\mathrm{FeSn}_{2}$ and $\mathrm{FeSn}$ is also assessed in the phase diagram of the Fe-Sn system in the region between $66-82 \mathrm{wt}$. \% of $\mathrm{Sn}$ and temperatures below $496^{\circ} \mathrm{C}$. The complete disappearing of $\mathrm{FeSn}_{2}$ from the surface only occurs at $600^{\circ} \mathrm{C}$, although it is decreasing since $400^{\circ} \mathrm{C}$ and it is already very small (18\% of the relative area) after annealing at $500{ }^{\circ} \mathrm{C}$. This is at slight variance with the phase diagram of the Fe-Sn system, but we must consider here that the substrate is a high carbon steel and so when we implant $\mathrm{Sn}^{+}$into it, we are dealing with a ternary (at least) system. So, small departures from the Fe-Sn system are expected to occur.
After annealing at $600^{\circ} \mathrm{C}$ we come again into a close agreement with the phase diagrams since, as described in Refs. 19 and 20, at this temperature only FeSn and free $\mathrm{Sn}$ in solid solution in the steel matrix are stable. The situation described by the CEMS spectrum after annealing at $700^{\circ} \mathrm{C}$ is consistent with a loss of $\mathrm{Sn}$ from the surface, due to the diffusion of the implanted ions. It is not possible, based on the CEMS spectrum only, to say anything conclusive about the nature of that part of Fig. 3(e) which is above the background level.

\section{Stainless steel}

The general picture for stainless steel below $600^{\circ} \mathrm{C}$ is similar to NSOH tool steel in that the Fe-Sn intermetallics are concerned. The new and very important aspect for practical purposes is the formation of the intermetallic $\mathrm{Ni}_{3} \mathrm{Sn}_{2}$ in the as-implanted sample. This remains stable and increases its proportion up to $600{ }^{\circ} \mathrm{C}$, where it represents $58 \%$ of the relative area of the spectrum. The rest of the CEMS spectrum after annealing at this temperature is due to FeSn. The intermetallic $\mathrm{FeSn}_{2}$ disappears completely after annealing at $500^{\circ} \mathrm{C}$.

If we look at the phase diagram for the Ni-Sn system ${ }^{22}$ we expect that $\mathrm{Ni}_{3} \mathrm{Sn}_{2}$ would remain stable at $700^{\circ} \mathrm{C}$. Indeed the CEMS spectrum taken after annealing at this temperature can be fitted exclusively with the quadrupole doublet of $\mathrm{Ni}_{3} \mathrm{Sn}_{2}$. The decomposition of FeSn should occur at a slightly higher temperature but, again, we must consider that we are dealing with a ternary system

A final verification of the consistency of the results here described with the phase diagram for $\mathrm{Ni}-\mathrm{Sn}$ was made by annealing at $900^{\circ} \mathrm{C}$. However the CEMS spectrum reflects the loss of ${ }^{119} \mathrm{Sn}$ from the surface. This spectrum could not be analyzed, although we can see that the line shape is similar to the previous one. This indicates that $\mathrm{Ni}_{3} \mathrm{Sn}_{2}$ is still stable at $900^{\circ} \mathrm{C}$, consistently with the phase diagram.

The identification of $\mathrm{Ni}_{3} \mathrm{Sn}_{2}$ precipitates is, as we said before, very important since Eliezer et al. ${ }^{17}$ have demonstrated that when this intermetallic is precipitated the hardness of a steel may be enhanced by a factor of more than two. Indeed, Dearnaley ${ }^{4}$ reported an enormous reduction on the wear rate of stainless steel when the surface is ion beam mixed with tin, and we can propose an explanation of this reduction in terms of the formation of $\mathrm{Ni}_{3} \mathrm{Sn}_{2}$ precipitates in the surface layers of the stainless steel.

\section{Conclusions}

In conclusion we can say that the use of ${ }^{119} \mathrm{Sn}$ CEMS allowed us to obtain a reasonable characterization of the phases formed during implantation of $\mathrm{Sn}^{+}$ions into iron and steels, as well as the behavior of these systems under thermal annealing.

The agreement with phase diagrams for the Fe-Sn and $\mathrm{Ni}$-Sn systems that we observed can certainly be used for future applications. These applications can be in high temperature oxidation (we have already tested the behavior of the NSOH tool steel implanted with $\mathrm{Sn}$ with excellent results) where the formation of $\mathrm{FeSn}_{2}$ indicates that good re- 
sults must be expected, as well as in wear resistance.

Further work is in progress in the characterization of the systems here investigated using other techniques of surface analysis, and we are also doing ${ }^{57} \mathrm{Fe}$ CEMS investigations of the same samples of the present work.

\section{ACKNOWLEDGMENTS}

The authors are very grateful to the Ion Crystal Interactions Group and Dr. G. Longworth from Harwell, for the solid help during part of the experimental work. We acknowledge also our colleagues, Professor F. C. Zawislak, Professor P. J. Viccaro, and Professor W. H. Schreiner, for the careful reading of the mansucript. This work was supported in part by FINEP, CAPES, and CNPq (Brasil).

${ }^{1}$ I. J. R. Baumvol, J. Appl. Phys. 52, 4583 (1981).

${ }^{2}$ I. J. R. Baumvol, R. E. J. Watkins, G. Longworth, and G. Dearnaley, Inst. Phys. Conf. Ser, 54, 201 (1980).

${ }^{3} G$. Dearnaley, Proceedings of the Denton Conference on Research and Industrial Applications of Accelerators (November, 1980), p. 86.

${ }^{4} \mathrm{G}$. Dearnaley, in Proceedings of the 4th International Conference on Ion Implantation: Equipment and Techniques, edited by $\mathrm{H}$. Ryssell and $\mathrm{H}$. Glawisching Springer Series in Electrophysics (Springer, Berlin, 1982), Vol. 11 , p. 332 .
${ }^{5}$ I. J. R. Baumvol, Phys. Status Solidi A 67, 287 (1981)

'R. E. S. Watkins, Harwell, Internal Report (1980).

${ }^{7} \mathrm{G}$. Dearnaley, Ion Implantation Into Metals, edited by V. Ashworth, W. A. Grant, and R. P. M. Procter (Pergamon, Oxford, 1982), p. 180.

${ }^{\text {R}}$ S. Mishra and M. K. Asundi, Can. Met. Quart. 11, 69 (1972).

${ }^{9} \mathrm{H}$. Leidheiser, Jr., The Corrosion of Copper, Tin and Their Alloys (Wiley, New York, 1971\%.

"G. P. Huffman and F. E. Huggins, in Mossbauer Spectroscopy and Its Chemical Applications, edited by J. G. Stevens and G. K. Shenoy. Adv. Chem. Ser. 194, 265 (1981).

${ }^{11 G}$. Longworth and R. Atkinson, in Mössbauer Spectroscopy and Its Chemical Applications, edited by J. G. Stevens and G. K. Shenoy, Adv. Chem. Ser. 194, 101 (1981).

${ }^{12}$ M. J. Tricker, in Mössbauer Spectroscopy and Its Chemical Applications, edited by 1. G. Stevens and G. K. Shenoy, Adv. Chem. Ser. 194, 63 (1981).

${ }^{13}$ G. Trumpy, E. Both, C. Djéga-Mariadassou, and P. Lecocq, Phys. Rev. B 2, 3477 (1970).

${ }^{14}$ I. Vincze and A. T. Aldred, Phys. Rev. B 9, 3845 (1974).

${ }^{15} \mathrm{G}$. P. Huffman and G. R. Dunmyre, J. Electrochem. Soc. 125, 1652 (1978).

"V. I. Nikolaiev, Yu. I. Shcherbina, and S. S. Yakimov, J. Exp. Theoret. Phys. (USSR) 45, 1277 (1963).

${ }^{17}$ Z. Eliezer, B. Z. Weiss, M. Ron, and S. Nadiv. J. Appl. Phys. 44, 419 (1973).

${ }^{18}$ H. Z. Dokuzogus, L. H. Bowen, and H. H. Stadelmaier, J. Phys. Chem. Solids 31, 1565 (1970).

${ }^{19}$ C. A. Edwards and A. Preece, J. Iron Steel Instrum. 124, 41 11931).

${ }^{20}$ W. F. Ehret and A. F. Westgren, J. Am. Chem. Soc. 55, 1339 (1933).

${ }^{21}$ W. D. Jones and W. E. Hoare, J. Iron Steel Instrum. 129, 273 (1934).

${ }^{22}$ M. Hausen, Constitution of Binary Alloys (McGraw-Hill, New York, 19581 . 